\title{
The role of echocardiography in the diagnosis and management of patients with pulmonary hypertension
}

\author{
G. Habib* and A. Torbicki\#
}

ABSTRACT: Pulmonary hypertension (PH) is defined as an increased mean pulmonary artery pressure $\left(\bar{P}_{\mathrm{pa}}\right)>25 \mathrm{mmHg}$ at rest as assessed by right heart catheterisation (RHC). However, this technique is invasive and noninvasive alternatives are desirable for early diagnosis of PH. Although estimation of systolic pulmonary arterial pressure is easily obtained using Doppler echocardiography, cases of under- and over-estimations are not rare and direct measurement of $\bar{P}_{\text {pa }}$ is not possible using this method. Therefore, echocardiography should be considered as a tool for assessment of the likelihood rather than the definite presence or absence of PH. Transthoracic echocardiography may be useful for noninvasive screening of patients at risk of $\mathrm{PH}$. On the basis of an echocardiographic assessment, patients showing signs suggestive of PH can be referred for a confirmatory RHC. A number of variables measured during echocardiography reflect the morphological and functional consequences of $\mathrm{PH}$ and have prognostic value. The presence of pericardial effusion, reduced tricuspid annular plane excursion and right atrial enlargement are associated with a poorer prognosis. Echocardiography is also an important procedure for monitoring the response of patients to therapy, and is recommended 3-4 months after initiation of, or a change in, therapy. Echocardiographic assessment as part of a goal-oriented approach to therapy is essential for the effective management of $\mathrm{PH}$ patients.

KEYWORDS: Diagnosis, echocardiography, prognosis, pulmonary hypertension

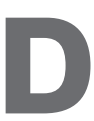

efinitive diagnosis of pulmonary hypertension $(\mathrm{PH})$ requires an elevated mean pulmonary arterial pressure $\left(\bar{P}_{\mathrm{pa}}\right)$ of $\geqslant 25 \mathrm{mmHg}$ at rest measured by right heart catheterisation (RHC) [1]. Although RHC is now a relatively safe procedure, it is invasive and impractical to perform in patients for whom it is not clearly indicated. Consequently there is a clear need for noninvasive procedures that aid diagnosis and allow identification of patients for whom diagnostic RHC is warranted, because of a high likelihood of the existence of $\mathrm{PH}$.

Transthoracic echocardiography (TTE) is one such tool and is widely available and safe. In addition to its role in diagnosis, it can be used to screen for high-risk patient populations, to assess prognosis and to monitor disease stability and response to treatment. These applications for TTE are presented in this article and the limitations of the procedure are discussed.

\section{DIAGNOSTIC VALUE OF} ECHOCARDIOGRAPHY AND ITS ROLE IN SCREENING PATIENTS AT RISK OF DEVELOPING PULMONARY ARTERIAL HYPERTENSION

Assessment of pulmonary arterial pressure

A number of echocardiographic variables correlate with right heart haemodynamics, including pulmonary arterial pressure $(P$ pa $)$, and are therefore of interest in the diagnosis of $\mathrm{PH}$. Noninvasive assessment of $P$ pa has always been difficult. Most of the methods used to estimate $P$ pa before the era of Doppler echocardiography were indirect. Such methods took advantage of the detectable consequences of right ventricular pressure overload on right ventricular morphology and function. For example, echocardiographic measurement of right ventricular enddiastolic dimension indexed for body surface area was reported to correlate with $\bar{P}_{\text {pa }}$ in patients with chronic $\mathrm{PH}$, but this correlation
AFFILIATIONS

*Hôpital La Timone, Marseille, France.

\#Institute of Tuberculosis and Lung Diseases, Warsaw, Poland.

CORRESPONDENCE

G. Habib

Service de Cardiologie

Hôpital La Timone

Boulevard Jean Moulin

13005 Marseille

France

E-mail: gilbert.habib@free.fr

Received:

Aug 242010

Accepted after revision:

Sept 112010

PROVENANCE

Publication of this peer-reviewed article was supported by Actelion Pharmaceuticals Ltd, Switzerland (unrestricted grant, European Respiratory Review issue 118).

European Respiratory Review Print ISSN 0905-9180 Online ISSN 1600-0617 
was not sufficiently robust to allow for $P$ pa estimation in individual patients [2-4]. Moreover, right ventricular dilation could be caused by its primary failure or increased preload.

Two principal approaches based on Doppler echocardiography were suggested to predict $P$ pa; assessment of right ventricular systolic and diastolic time intervals and measurements of peak velocities of valvular regurgitations and shunts affecting the right heart. Initial reports from clinical trials were enthusiastic both for pulsed wave Doppler estimates of $\bar{P}_{\text {pa }}$ based particularly on the interval from the start to peak velocity of right ventricular ejection (acceleration time (AcT)) as well as continuous wave Doppler predictions of systolic and diastolic pressures derived from tricuspid and pulmonary valvular regurgitation velocity, respectively.

AcT was reported to decrease with increasing Ppa [5]. In addition, mid-systolic deceleration of right ventricular ejection into the pulmonary artery, whenever present, occurred earlier with higher $P_{\text {pa }}$ [6]. Reports suggested excellent correlations between AcT and P pa, particularly when measured simultaneously [7], and offered regression equations for noninvasive pressure calculations. However, significant differences between these equations precluded their universal application [8]. Moreover, acutely induced changes in $P$ pa were not accurately reflected by respective changes in AcT [9]. While heart rate [10] and the presence of tricuspid regurgitation apparently did not affect AcT [11], several other factors did; at the same level of $P$ pa AcT time tended to be longer in patients with low cardiac index [12] and with increased pulmonary flow due to pre-tricuspid shunts [11]. In addition, AcT tended to be shorter with more distal Doppler sample volume positions $[13,14]$ in individuals with body surface area $>2.0 \mathrm{~m}^{2}$ and in adults $>30$ yrs old [15]. Due to these limitations, the measurement of time intervals with pulsed wave Doppler as a method of estimation of $P$ pa was practically eliminated from clinical practice, while their potential role in assessment of components of pulsatile haemodynamics still remain largely unexplored [16, 17].

In contrast to time intervals, estimation of $P$ pa using continuous Doppler and jet velocity methods were based on simple haemodynamic laws. The pressure gradient (PG) driving blood through an orifice can be calculated according to the simplified Bernoulli equation as $\mathrm{PG}=4 \mathrm{~V}^{2}(\mathrm{mmHg})$, where $\mathrm{V}$ represents the peak jet velocity, not accounting for orifice geometry and blood viscosity $[16,18]$. Consequently, the peak jet velocity of pulmonary insufficiency [19] as well as peak flow velocities across a ventricular septal defect $[20,21]$ or patent ductus arteriosus [22] allow for calculations of $P$ pa. However, tricuspid valve regurgitant jet is the most widely used for this purpose [23]. With modern equipment it is detectable in the majority of patients and its Doppler spectrum can be enhanced by intravenous injection of echocardiographic contrast, further increasing the number of tracings suitable for evaluation [24, 25].

For calculation of systolic $P$ pa $(P$ pa,syst), stenosis of right ventricular outflow must be excluded, and an estimate of the right atrial pressure $(P r a)$ should be added to the tricuspid insufficiency pressure gradient (TIPG): $P$ pa,syst $=$ TIPG + estimated Pra. Estimation of Pra based on echocardiographic inferior vena cava (IVC) collapsibility index has been suggested. This index is calculated by subtracting inspiratory from expiratory IVC diameter, and dividing the result by expiratory IVC diameter [26, 27].

While reported correlations between $P$ pa,syst and its Doppler estimate were excellent, the standard error of estimation remained above $5 \mathrm{mmHg}$, affecting the precision of $P$ pa estimation in an individual patient [28]. In an early landmark trial, the reported inter- and intra-observer variabilities were low [23], contrasting with both everyday clinical experience and results of a recent re-evaluation of the method [29]. In a recent trial, although $P$ pa and Doppler measurements were obtained within $1 \mathrm{~h}$ of each other in 65 clinically stable patients with $\mathrm{PH}$ and there was no systematic over- or underestimation of directly measured $P$ pa,syst with the tricuspid jet method, 95\% limits of agreement showed a very broad range of potential error (+38.8 to $-40.0 \mathrm{mmHg}$ ). Doppler echocardiography resulted in over- or under-estimation of $P$ pa,syst by more than $10 \mathrm{mmHg}$ in $48 \%$ of cases [30]. Pressure underestimation in 12 out of 15 patients exceeded $20 \mathrm{mmHg}$ while pressure overestimates exceeded $20 \mathrm{mmHg}$ in six patients. Half of all the cases of $P$ pa,syst overestimation were related to Pra overestimation by echocardiography but disagreement between systolic right ventricle-right atrial gradient by two methods was also significant [30].

A correlation was observed between diastolic $P$ pa and Doppler-derived end-diastolic pressure gradient $(\mathrm{r}=0.91)$ [31]. However, when directly compared in the same patients, Doppler-derived pressure calculations based on diastolic velocities across the pulmonary valve were less accurate than those based on tricuspid jet velocity measurements $(r=0.83$ versus 0.98 , respectively) [32].

Joint evaluation of tricuspid and pulmonary regurgitant jets allows for complete reconstruction of the $P$ pa curve from which $\bar{P}$ pa could be theoretically calculated [32]. A simplified strategy based on measurement of the peak (early) diastolic pulmonary to right ventricular pressure gradient derived from the Doppler flow profiles has also been suggested [31].

Extrapolation of $\bar{P}_{\text {pa }}$ from the Doppler estimate of $P_{\text {pa,syst }}$ assessed from TIPG can also be considered. Data suggesting a strong correlation between $P$ pa,syst and $\bar{P}$ pa, regardless of the clinical diagnosis of a patient, seem encouraging. Measured with high-fidelity tip catheters, systolic $\bar{P}_{\text {pa }}$ equalled $0.61(P$ pa,syst $)+2 \mathrm{mmHg}$, with negligible error $[33,34]$. Whether such direct measurement of $P$ pa,syst might be substituted in the equation by its Doppler estimate remains to be verified.

\section{Echocardiographic diagnosis of $\mathrm{PH}$}

Noninvasive diagnosis of $\mathrm{PH}$ is tempting but risky in view of the discussed limitations of all available echocardiographic and Doppler methods. Recent clinical practice guidelines have suggested that echocardiographic conclusions should be limited to assignment of the level of probability of $\mathrm{PH}$ rather than confirmation or exclusion of its presence in individual subjects [1].

One of the obvious problems with noninvasive diagnosis of $\mathrm{PH}$ is that echocardiography provides us in most cases with an estimate of $P$ pa,syst rather than $\bar{P}_{\mathrm{pa}}$, on which definition of $\mathrm{PH}$ is actually based (i.e. $\bar{P}$ pa $\geqslant 25 \mathrm{mmHg}$ at rest). The suggested criteria for the three levels of probability of $\mathrm{PH}$ acknowledged 
existing data on upper limits of Doppler-derived $\bar{P}_{\text {pa }}$ estimates in normal people. It also attempted to identify a cut-off value for the Doppler estimate of $P$ pa,syst corresponding to the RHC definition of $\mathrm{PH}$.

Among 3,212 patients with otherwise normal TTE and no clinically suspected diseases potentially leading to elevated $P$ pa, mean peak tricuspid jet velocity was $2.6 \mathrm{~m} \cdot \mathrm{s}^{-1}$ and TIPG was $18.0 \pm 4.7 \mathrm{mmHg}(95 \% \mathrm{CI} 8.8-27.2 \mathrm{mmHg}$ ) [35]. Multiple linear regressions revealed that age, body mass index (BMI), sex, left ventricular ejection fraction and clinical referral category independently influenced tricuspid velocity. In subjects aged over $60 \mathrm{yrs}$, and/or presenting with BMI $>30 \mathrm{~kg} \cdot \mathrm{m}^{-2}$, the $95 \%$ confidence interval for TIPG measurement slightly exceeded $30 \mathrm{mmHg}$ [35]. Also, according to the Chemla equation a TIPG of $31 \mathrm{mmHg}$, assuming $P$ ra at $5 \mathrm{mmHg}$, would suggest an $\bar{P}_{\text {pa }}$ of $24 \mathrm{mmHg}[33,34]$. Thus, based on existing population and pathophysiological data it appears justified to consider tricuspid jet velocities exceeding $2.8 \mathrm{~m} \cdot \mathrm{s}^{-1}$ at rest, and corresponding to a TIPG greater than $31 \mathrm{mmHg}$, as elevated, except in elderly and/ or very obese patients.

Consequently, if peak tricuspid jet velocity is $<2.8 \mathrm{~m} \cdot \mathrm{s}^{-1}$ the diagnosis of $\mathrm{PH}$ is "unlikely". Conversely, when the peak tricuspid jet velocity is $>3.4 \mathrm{~m} \cdot \mathrm{s}^{-1}$, the diagnosis of $\mathrm{PH}$ is considered "likely". In case of intermediate tricuspid jet velocities $\left(2.8-3.4 \mathrm{~m} \cdot \mathrm{s}^{-1}\right) \mathrm{PH}$ is considered "possible". Criteria proposed by the recent guidelines also accounted for the presence or absence of other echocardiographic signs suggesting right ventricular pressure overload. For example, if morphology, function of the right ventricle and/or systolic time intervals such as AcT and mid-systolic deceleration of right ventricular ejection are suggestive of $\mathrm{PH}$, such diagnosis should be considered "possible" even with a Doppler estimate of $P$ pa,syst within the normal range (table 1 ).

\section{Echocardiographic screening for $\mathrm{PH}$}

Acknowledging the limitations of TTE in definitively diagnosing $\mathrm{PH}$, the echocardiographic estimation of the likelihood of $\mathrm{PH}$ is among the key elements in the decision-making process, related to the need and timing of RHC in patients with suspected PH. Tricuspid jet velocity has also been a central variable in trials that assessed the possibility of noninvasive "screening" of patients considered to be at increased risk of pulmonary arterial hypertension (PAH) or chronic thromboembolic PH (CTEPH). Since these programmes largely focused on symptomatic (dyspnoeic) rather than asymptomatic patients, the term screening is not entirely appropriate.
However, early detection was the main purpose of the trials related to $\mathrm{PAH}$, which was clinically justified by the evidence of better treatment results and outcome in patients with less advanced disease at the time of diagnosis.

Scleroderma patients have a recognised predisposition to develop $\mathrm{PAH}$. A retrospective trial assessed 137 patients with scleroderma regardless of the presence or absence of lung fibrosis [36]. The TIPG cut-off value of $30 \mathrm{mmHg}$ (corresponding to an $P$ pa,syst of $35 \mathrm{mmHg}$ and tricuspid jet velocity of $\sim 2.75 \mathrm{~m} \cdot \mathrm{s}^{-1}$ ) had $88 \%$ sensitivity but only $42 \%$ specificity for $\mathrm{PH}$. Tricuspid gradients of $>45 \mathrm{mmHg}$, (corresponding to an $P$ pa,syst $>50 \mathrm{mmHg}$ and tricuspid jet velocity $>3.35 \mathrm{~m} \cdot \mathrm{s}^{-1}$ ) had $97 \%$ specificity but only $47 \%$ sensitivity. In another trial, which used TIPG $>40 \mathrm{mmHg}$ as a cut-off value, $\mathrm{PH}$ was confirmed in all 32 scleroderma patients who were evaluated with RHC [37]. However, false-negative results for this cut-off value could not be assessed due to trial design. In the ongoing DETECT study in scleroderma patients, echocardiography is one of several tools being prospectively evaluated against RHC for sensitivity, specificity and predictive value in identifying patients with $\mathrm{PAH}$ [38].

In a prospective assessment of 599 patients with scleroderma using Doppler echocardiography, all patients with a peak tricuspid jet velocity $>3.0 \mathrm{~m} \cdot \mathrm{s}^{-1}$ as well as those with $>2.5 \mathrm{~m} \cdot \mathrm{s}^{-1}$ and exertional dyspnoea qualified for RHC [39]. While only 14 out of 33 such patients had PH confirmed with $\mathrm{RHC}$, this allowed for early detection, since in most cases PH was mild. In an additional four patients, $\mathrm{PH}$ was diagnosed because of the rise in $\bar{P}_{\text {pa }}$ to $>30 \mathrm{mmHg}$ during exercise, but this is no longer included among PH diagnostic criteria [1]. A further trial assessed the prevalence of PAH in patients with HIV [40]. In this study 7,648 patients with HIV completed a questionnaire, which identified dyspnoea in 739 patients. Of these, 247 met criteria and agreed to participate in the trial. Among 18 patients with peak tricuspid jet velocity $>2.5 \mathrm{~m} \cdot \mathrm{s}^{-1}$ and dyspnoea only five were found to have PAH at RHC. Post hoc analysis after increasing the cut-off value of peak tricuspid jet velocity to $>2.8 \mathrm{~m} \cdot \mathrm{s}^{-1}$ reduced the number of positive echocardiographic results from 18 to seven, and the rate of false-positive results to $29 \%$.

Prospective echocardiographic screening of asymptomatic survivors of acute pulmonary embolism for CTEPH remains questionable. A recent Dutch prospective screening study enrolled 866 patients with a history of acute pulmonary embolism [41]. Echocardiographic criteria included peak tricuspid jet velocity of $2.8 \mathrm{~m} \cdot \mathrm{s}^{-1}$ and also pulmonary insufficiency

\section{TABLE 1 Echocardiographic criteria corresponding to various levels of likelihood of pulmonary hypertension (PH)}

Peak tricuspid jet velocity $\mathrm{m} \cdot \mathrm{s}^{-1}$

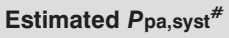

$\mathrm{mmHg}$

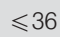

$\leqslant 36$

$37-50$

$>50$
Other echo signs of $\mathrm{PH}$ present
PH (grade of evidence) [1]

$\begin{array}{cc}\text { No } & \text { Unlikely (I-B) } \\ \text { Yes } & \text { Possible (Ila-C) } \\ \text { No } & \text { Possible (Ila-C) } \\ \text { Yes/no } & \text { Likely (I-B) }\end{array}$

: echo-Doppler estimate of systolic pulmonary arterial pressure (Ppa,syst) based on tricuspid jet method (right atrial pressure assumed to be 5 mmHg) 
jet velocity, AcT and the presence of morphological and functional consequences of $\mathrm{PH}$. All patients who met one or more of the six predefined echocardiographic criteria were suspected of having $\mathrm{PH}$ and underwent further standardised work-up including perfusion lung scintigraphy and RHC for pressure measurements. The final diagnosis assessed by an independent expert panel according to predefined criteria revealed $0.57 \%$ (95\% CI $0.02-1.2 \%$ ) prevalence of CTEPH. However, most of the patients with CTEPH were already identified because of clinical symptoms and signs. This occurred before they were invited for formal echocardiographic screening, which had very low additional diagnostic yield for CTEPH, and was not found practically useful by the authors [41]. A similar conclusion was recently extended to patients who reported new or increased dyspnoea after a previous episode of acute pulmonary embolism. Symptomatic CTEPH was considered if the $P$ pa,syst exceeded $40 \mathrm{mmHg}$ on echocardiography and the perfusion scan showed a perfusion defect on the lobar or segmental levels of the lungs. If these findings were positive, patients underwent further diagnostic workup, including pulmonary angiography with direct measurement of $\mathrm{Ppa}$, to confirm or refute the diagnosis of CTEPH. No additional patients were diagnosed as a result of echocardiographic examinations performed within this programme [42].

Screening appears to be more successful when higher cut-off levels for Ppa,syst are used to identify patients who should be referred for RHC. Among 101 candidates for liver transplant with Doppler estimate of $P$ pa,syst $>50 \mathrm{mmHg}$, all-cause $\mathrm{PH}$ was documented at RHC in 90 out of $101(90 \%)$ patients and $\mathrm{PAH}$ in 66 out of $101(65 \%)$ patients [43].

In summary, echocardiographic screening for $\mathrm{PAH}$ and CTEPH is not effective in asymptomatic patients at increased risk and requires better definition of both clinical and echocardiographic enrolment criteria in those patients at risk, who are mildly symptomatic. In the recent European Society of Cardiology (ESC)/European Respiratory Society (ERS) guidelines [1], echocardiographic screening is recommended in symptomatic patients with scleroderma (evidence level I-B), symptomatic patients with liver disease (evidence level I-B) or HIV (I-C) and may be considered in asymptomatic patients with scleroderma (evidence level IIb-C). The potential role of echocardiographic stress testing in the early diagnosis of $\mathrm{PH}$ will be addressed later in the article.

\section{ECHOCARDIOGRAPHIC EVALUATION OF THE CONSEQUENCES OF PH}

Assessment of the consequences of $\mathrm{PH}$ on left and right heart remodelling is one of the most important parts of the echocardiographic examination, because of its potential prognostic value. Since $\mathrm{PH}$ is a very severe disease with high mortality rate [44-48], the identification of noninvasive markers of a poor prognosis will be useful for patient management and follow-up. Several echocardiographic indices have been proposed [26, 49-51] and have the common objective of assessing the three main consequences of $\mathrm{PH}$ : right heart remodelling, impact on the left heart and RV dysfunction.

\section{Impact of $\mathrm{PH}$ on the right heart}

Severe $\mathrm{PH}$ frequently causes right ventricular and right atrial dilatation, abnormal inter-ventricular septal motion, right ventricular dysfunction, and dilatation of the superior and inferior vena cavae and hepatic veins, as well as pericardial effusion (fig. 1) [52]. The simplest parameter is the measurement of the right atrial dimensions, including right atrial diameter and area measured on a four chamber apical view (fig. 2). A right atrial area $>20 \mathrm{~cm}^{2}$ is abnormal [53] and an area $>27 \mathrm{~cm}^{2}$ has been associated with a poor prognosis [54].

Right ventricular measurements are more challenging because of the frequent presence of large trabeculations, and because of the complex morphology of the right ventricle. For this reason, no reference value exists concerning right ventricular volume measurement by echocardiography [53]. Measurement of the mid-cavity and basal right ventricular diameter in the apical four-chamber view at end-diastole is a simple method for quantification of right ventricular size. Right ventricular area measurement is another option [55] but has similar limitations. Right ventricular diastolic areas ranging from 11 to $28 \mathrm{~cm}^{2}$ have been reported; right ventricular area $>38 \mathrm{~cm}^{2}$ is severely abnormal [53]

\section{Impact of PH on the left heart and cardiac output}

Severe $\mathrm{PH}$ frequently causes compression of the left heart cavities, abnormal left ventricular filling, and decreased cardiac output [26, 50-52]. All of these are very important parameters for assessing the severity of $\mathrm{PH}$ consequences, and can be measured easily by echocardiography.

Left ventricular compression is frequently observed in $\mathrm{PH}$ and has been reported to have a prognostic value [56]. It may be quantified by the eccentricity index (fig. 3), measured as the ratio of the long axis to short axis diameters of the left ventricle, both in diastole and in systole [57]. The eccentricity index is calculated on the two-dimensional short-axis view of the left ventricle and may discriminate between right ventricular volume overload and pressure overload states. Right ventricular dilatation also causes abnormal left ventricular filling,

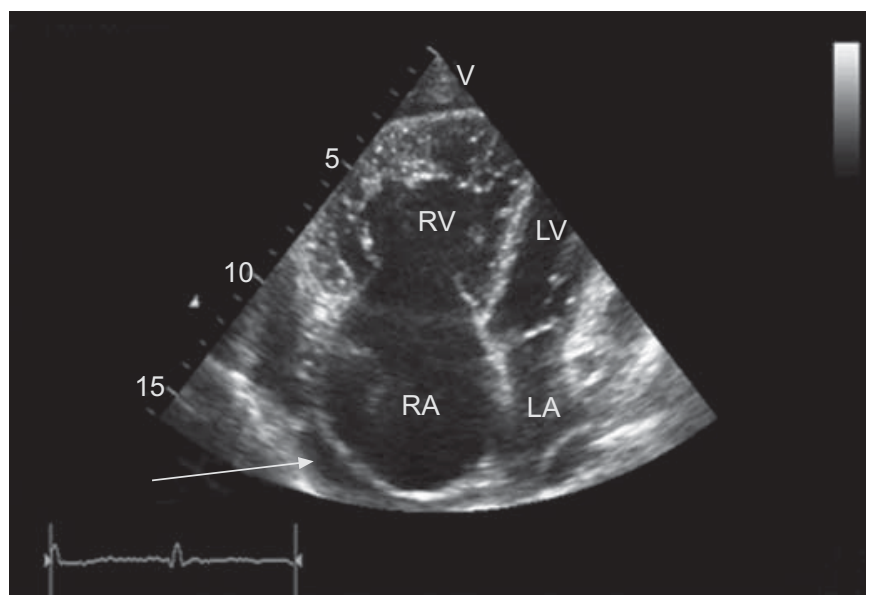

FIGURE 1. Typical echocardiographic features in a patient with severe pulmonary arterial hypertension. Dilatation of the right cavities, compression of the left cavities, presence of a pericardial effusion (arrow). RV: right ventricle; LV: left ventricle; RA: right atrium; LA: left atrium. 


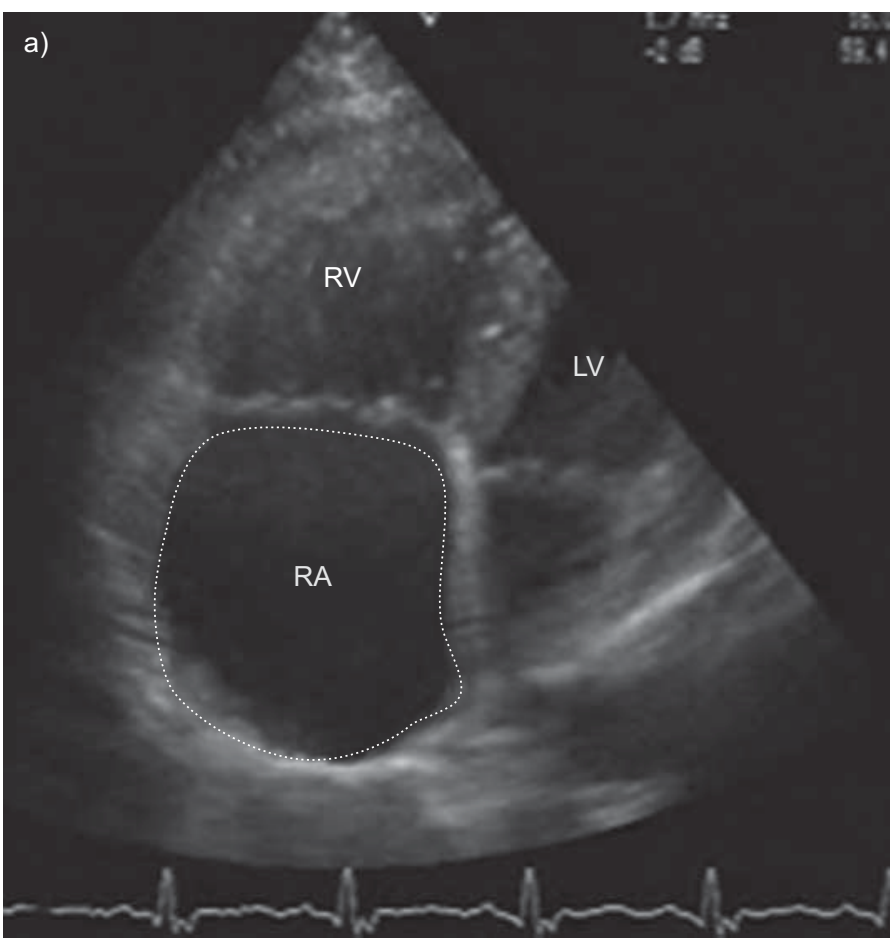

Right atrial area $\left(\mathrm{N}<20 \mathrm{~cm}^{2}\right)$

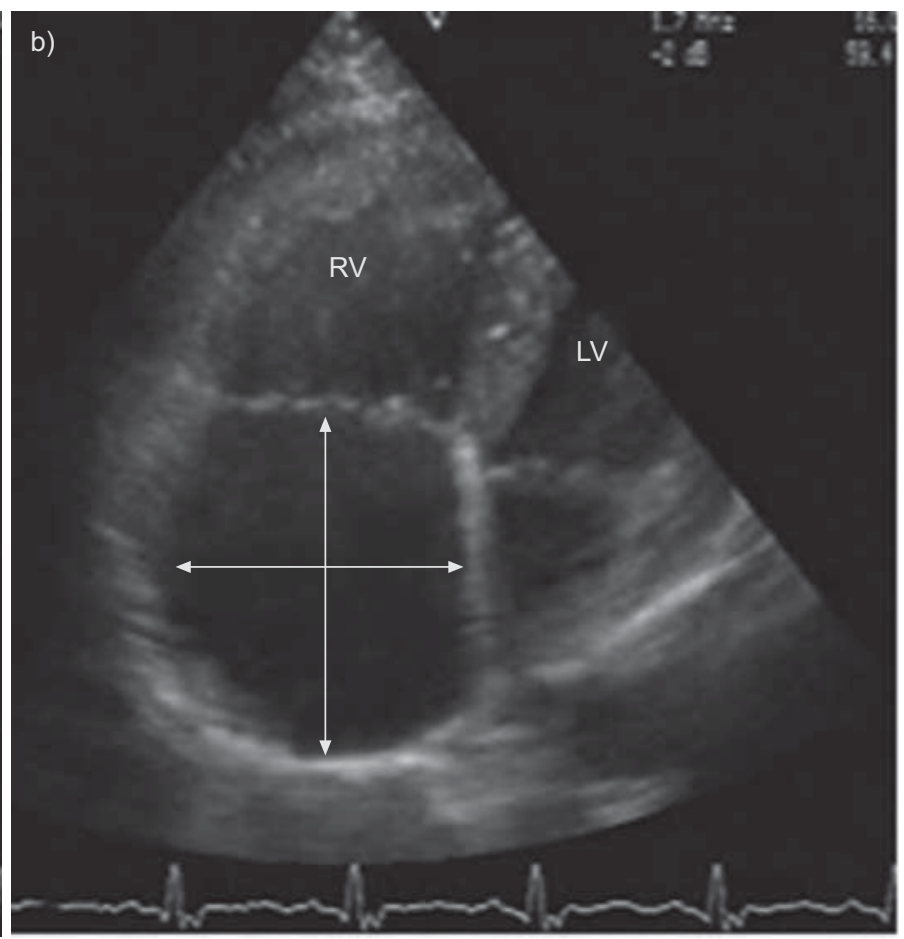

Right atrial transverse and supero-inferior diameters

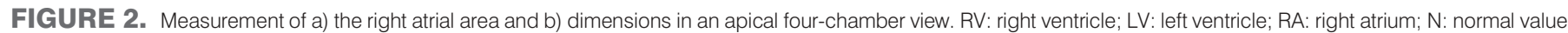

which may be assessed by the recording of the mitral inflow (fig. 4). A pattern of abnormal relaxation is frequently observed in severe PH [52]. Finally, one of the most important consequences of severe $\mathrm{PH}$ is a decrease in cardiac output. This parameter must be systematically assessed by TTE, using the combination of the left ventricular outflow tract diameter and the time-velocity integral of the aortic flow recorded by pulsed wave Doppler (fig. 4). Although this parameter suffers from some degree of inter-observer variability, it is a crucial measurement for the assessment of severity and follow-up of patients presenting with $\mathrm{PH}$ [58].

\section{Evaluation of right ventricular dysfunction}

The main consequence of severe $\mathrm{PH}$ is right ventricular dysfunction. However, several caveats limit the use of right ventricular function parameters. First, there is no good geometric model allowing the calculation of right ventricular ejection fraction [53]. Secondly, the large apical trabeculations of the right ventricle make the endocardial delineation more difficult to obtain than for the left ventricle. In addition, the geometry of the right ventricle itself is complex, with two different chambers oriented in two different planes [59]. In addition, several measurements of the right ventricle are loaddependent and of limited accuracy [26]. Finally, longitudinal fibres are predominant in the right ventricle, making right ventricular radial contraction, as assessed by ejection fraction, an imperfect reflection of its true contractile properties.

For these reasons, no single parameter appears sufficient today to give an adequate assessment of right ventricular function. Rather, a combination of the following parameters must be used $[26,50,60]$.
1) The subjective evaluation of right ventricular function has been used for a long time but suffers from lack of precision and of reproducibility [53]. A more precise evaluation can be obtained by the measurement of the right ventricular area, in systole and diastole, allowing the calculation of the right ventricular shortening fraction (RVSF). The RVSF is a relatively simple method of assessing right ventricular function, which correlates well with magnetic resonance imaging (MRI) measurements, but is dependent on the quality of the echocardiographic images [61]. Measurement of right ventricular ejection fraction based on volume measurement has been attempted. However, whatever the method of calculation (e.g. Simpson's method or area-length method) it suffers from the same limitations as volume measurements. Right ventricular ejection fraction is load dependent [26] and no reference value has been proposed in the recent recommendations from the American and European Societies of Echocardiography [53].

2) Tei index is a simple parameter used to assess the global function of the right ventricle. This global myocardial performance index needs the measurements of both the tricuspid inflow and the right ventricular outflow by pulsedwave Doppler (fig. 5). Normal values are $0.28 \pm 0.04$, and the Tei index gets more prolonged with more severe right ventricular dysfunction $(0.93 \pm 0.34$ in patients with $\mathrm{PAH})$ [62]. Tei index has the advantage of being relatively independent of loading conditions and of representing a global estimate of right ventricular function independent of geometric assumptions [26], but is limited by its mode of calculation based on two different cardiac cycle measurements. Similar information can be obtained using tissue Doppler imaging (TDI), which has the advantage of obtaining both measurements during the same cardiac cycle [64]. 

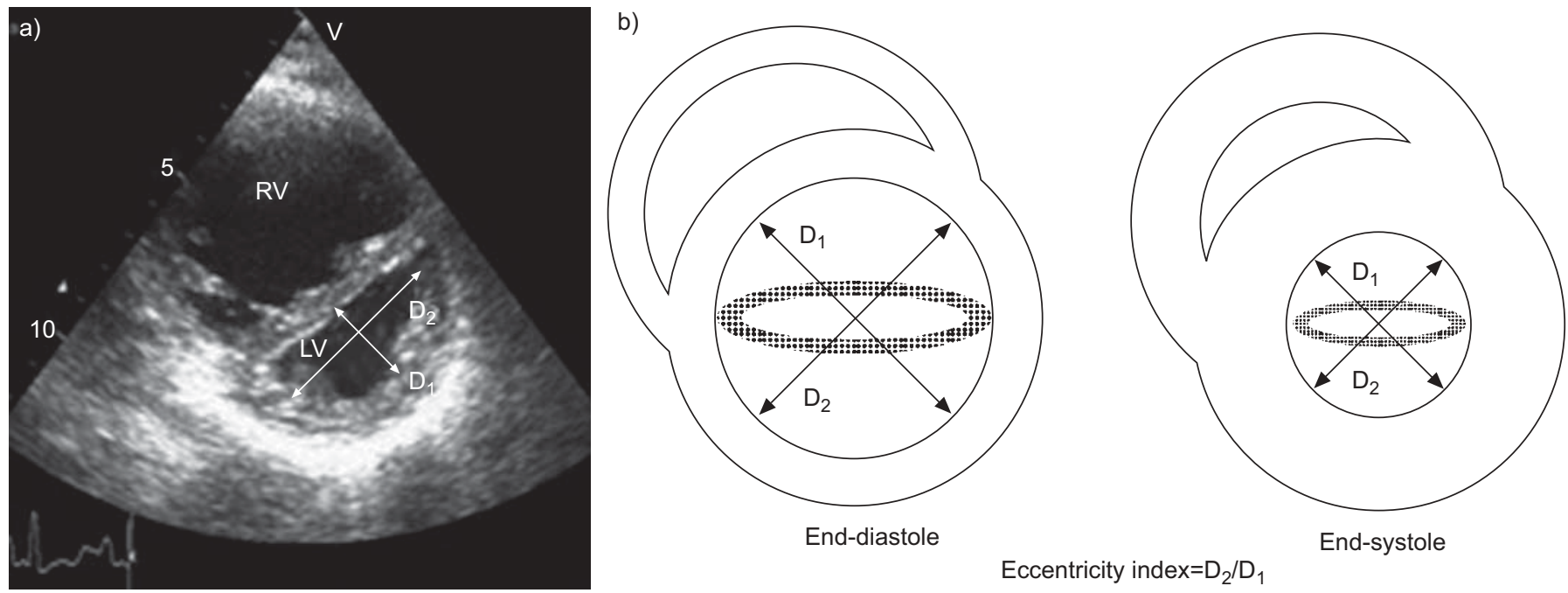

FIGURE 3. Measurement of the eccentricity index. RV: right ventricle; LV: left ventricle. Reproduced from [57] with permission from the publisher.

3) Another simple parameter for evaluating right ventricular function is the tricuspid annulus plane systolic excursion (TAPSE). TAPSE is a surrogate of right ventricular function, as longitudinal fibres are predominant in the right ventricle. This parameter can be obtained easily by M-mode echocardiography of the right ventricular annulus (fig. 6). Normal values are $>20 \mathrm{~mm}$ and are severely reduced in case of right ventricular dysfunction [66]. However, TAPSE suffers from several limitations [26], including angle and load dependency. In addition, TAPSE focuses only on a small part of the right ventricular myocardium, is affected by the overall heart motion, and thus cannot be considered as a real surrogate of entire right ventricular function [26].

4) Similar information can be obtained with TDI of the tricuspid annulus [67]. This technique allows a very simple evaluation of the tricuspid annulus systolic and diastolic velocities (fig. 7). In a series of 44 patients with heart failure, MELuZín et al. [67] found that the peak systolic tricuspid annular velocity significantly correlated with the right ventricular ejection fraction assessed by first-pass radionuclide ventriculography. Normal values were $15.5 \pm 2.6 \mathrm{~cm} \cdot \mathrm{s}^{-1}$ in healthy subjects. A value $<11.5 \mathrm{~cm} \cdot \mathrm{s}^{-1}$ enables right ventricular dysfunction to be predicted (ejection fraction $<45 \%$ ) with a sensitivity of $90 \%$ and a specificity of $85 \%$. More recently, velocities and acceleration during the isovolumic contraction phase (fig. 7) have been studied using TDI of the basal right ventricular free wall [68]. Isovolumic myocardial acceleration has been reported to be less affected by preload and afterload and thus to be the most reliable contractility index $[68,69]$. In a recent series [69], TAPSE, systolic velocities and isovolumic contraction parameters were able to detect early right ventricular dysfunction in patients with systemic sclerosis.

In summary, although these parameters require further validation in patients with $\mathrm{PH}$, TDI of the right ventricular annulus and basal free wall has the advantage of being able to obtain several parameters of right ventricular function from a single cardiac cycle, including systolic and diastolic velocities, isovolumic contraction phase parameters and Tei index. Among the new echocardiographic techniques, strain imaging

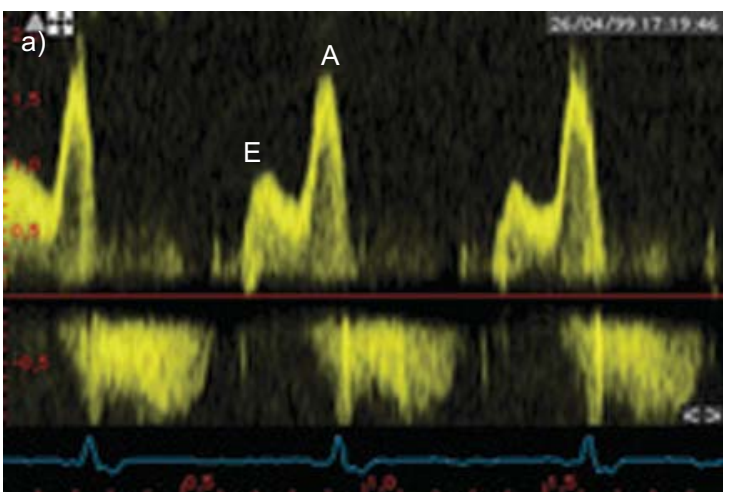

Abnormal LV filling
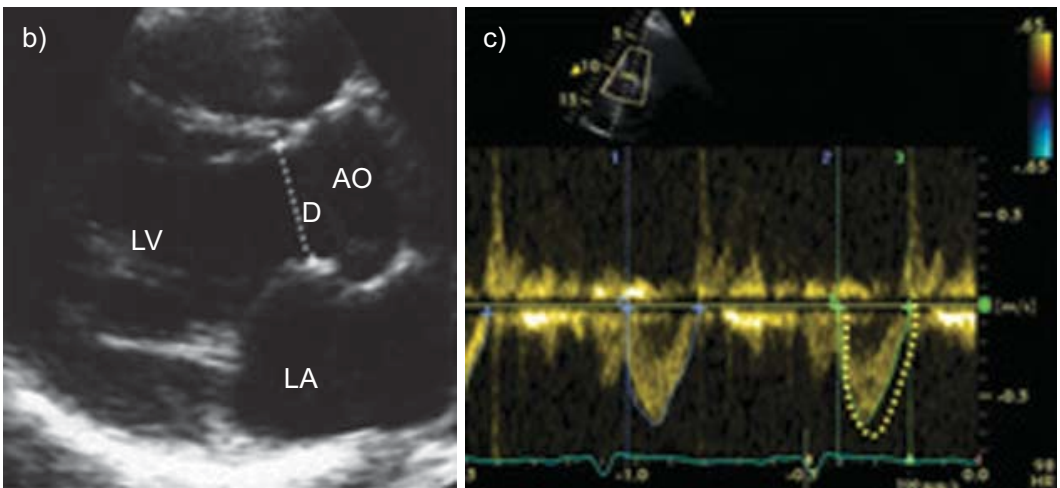

Aortic annulus diameter and aortic TVI

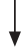

Low cardiac output

FIGURE 4. Left heart consequences of pulmonary hypertension. a) Abnormal left ventricular filling by pulsed-wave Doppler. b and c) Measurement of cardiac output using Doppler echocardiography. LV: left ventricle; LA: left atrium; AO: aorta; D: aortic annulus diameter; TVI: time velocity integral. 

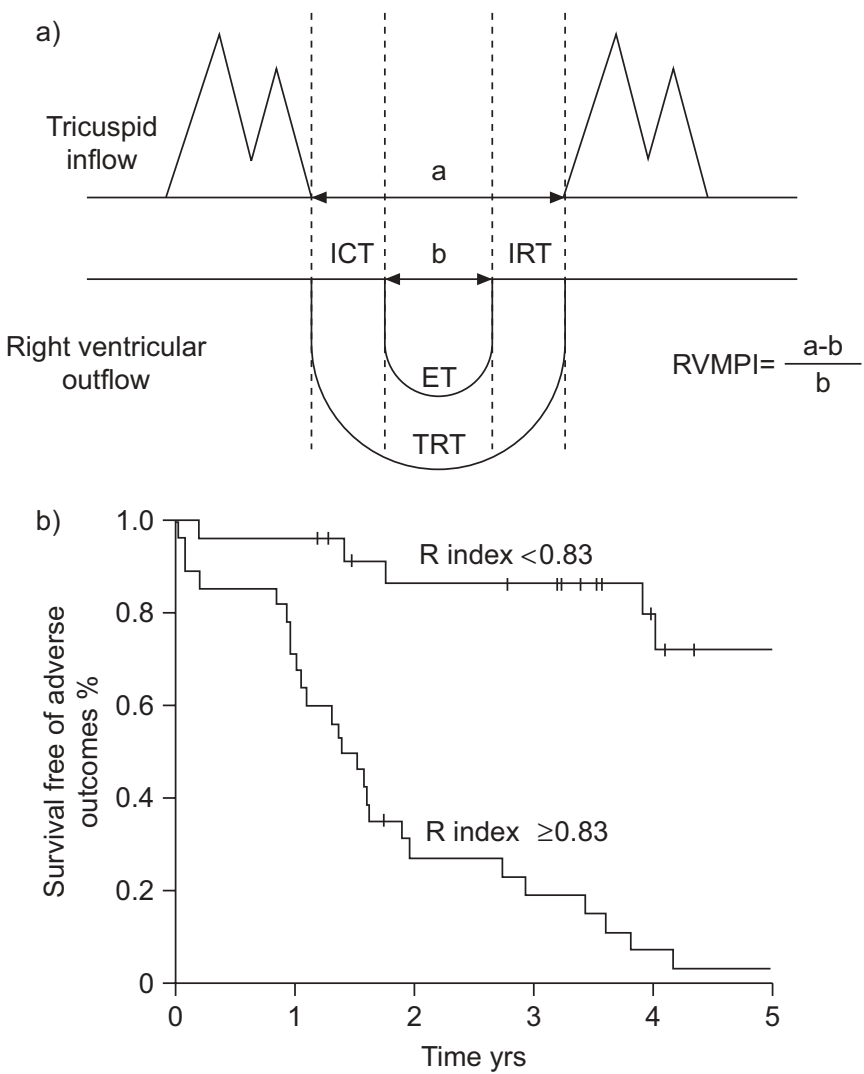

Index $\geq 0.8325$ $24(96 \%) 19(87 \%)$ $20(71 \%) 7(28 \%)$

$8(73 \%)$ Index $<0.8328$$$
20(71 \%) 7(28 \%)
$$

FIGURE 5. Assessment of the right ventricle global performance by the Tei index. a) Method of measurement of Tei index. Right ventricle myocardial performance index (RVMPI) ([a-b]/b) is calculated by measuring two intervals: 1) $a$ is interval between cessation and onset of tricuspid inflow; and 2) $b$ is ejection time (ET) of right ventricular outflow. ICT: isovolumetric contraction time; IRT: isovolumetric relaxation time; TRT: tricuspid regurgitation time. Reproduced from [62] with permission from the publisher. b) Prognostic value of Tei index. Reproduced from [63] with permission from the publisher.

and three-dimensional echocardiography have been shown to be potentially useful to assess right ventricular function [70].

\section{Other consequences of $\mathbf{P H}$ assessed by echocardiography}

Two other important consequences of PH may be assessed by echocardiography. Pericardial effusion is usually of minor importance. However, in some circumstances it can contribute to abnormal left and right ventricular function [71] and is of prognostic value in $\mathrm{PH}$. Right to left shunting through a patent foramen ovale is observed frequently in severe $\mathrm{PH}$ with elevated Pra. It may be easily diagnosed by intravenous injection of microbubbles using a peripheral line. Severe right to left atrial shunting may explain hypoxemia observed in some patients with $\mathrm{PH}$.

\section{ECHOCARDIOGRAPHY FOR PROGNOSTIC ASSESSMENT AND FOLLOW-UP OF PATIENTS WITH PH} The natural history of $\mathrm{PH}$ is marked by frequent complications and a high mortality rate [44-48]. Besides its diagnostic value and its role in the assessment of consequences of $\mathrm{PH}$, echocardiography is also useful for the prognostic assessment of $\mathrm{PH}$.

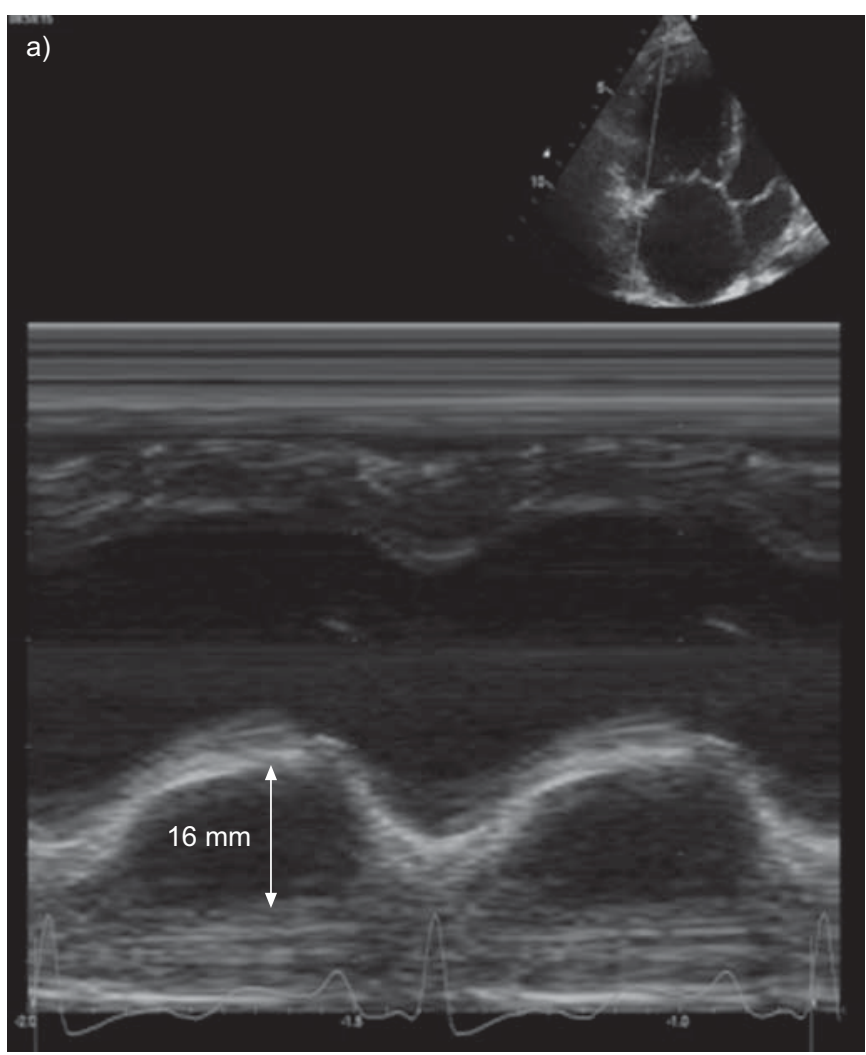

b)

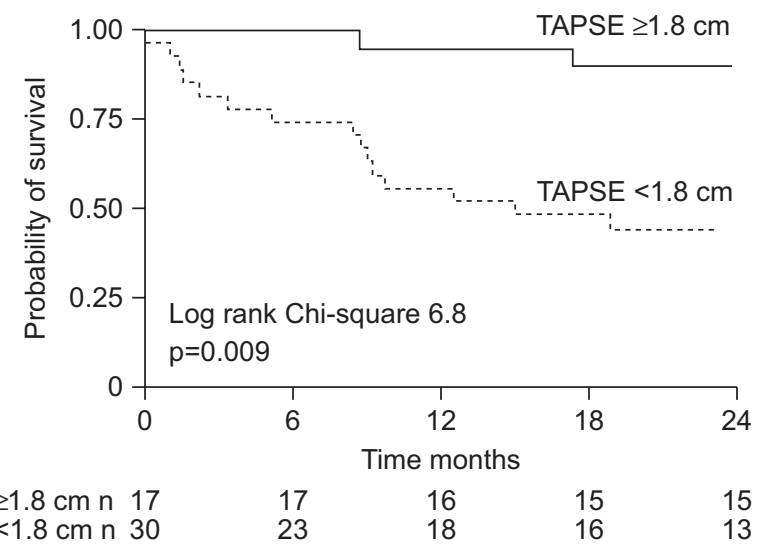

TAPSE $\geq 1.8 \mathrm{~cm} \mathrm{n} 17$ TAPSE $<1.8 \mathrm{~cm} \mathrm{n} 30$ 23

FIGURE 6. Measurement of the tricuspid annulus plane systolic excursion (TAPSE). a) Method of measurement of TAPSE by M-mode echocardiography. b) Prognostic value of TAPSE. Reproduced from [65] with permission from the publisher.

Several of the parameters measurable with echocardiography discussed above have been shown by multivariate analyses to carry a prognostic value. These include right atrial area [54], eccentricity index [56], presence of a pericardial effusion [71], Tei index [63] and TAPSE [65]. A multicentre study found that the most potent predictive markers of death in $\mathrm{PH}$ were right atrial size, pericardial effusion and eccentricity index [56]. In the recent European guidelines however, only pericardial effusion and TAPSE have been selected as major prognostic indicators on the basis that they can be measured in the majority of patients [1], although several other indices have the potential to help the clinician in the prognostic assessment of patients with $\mathrm{PH}$. 


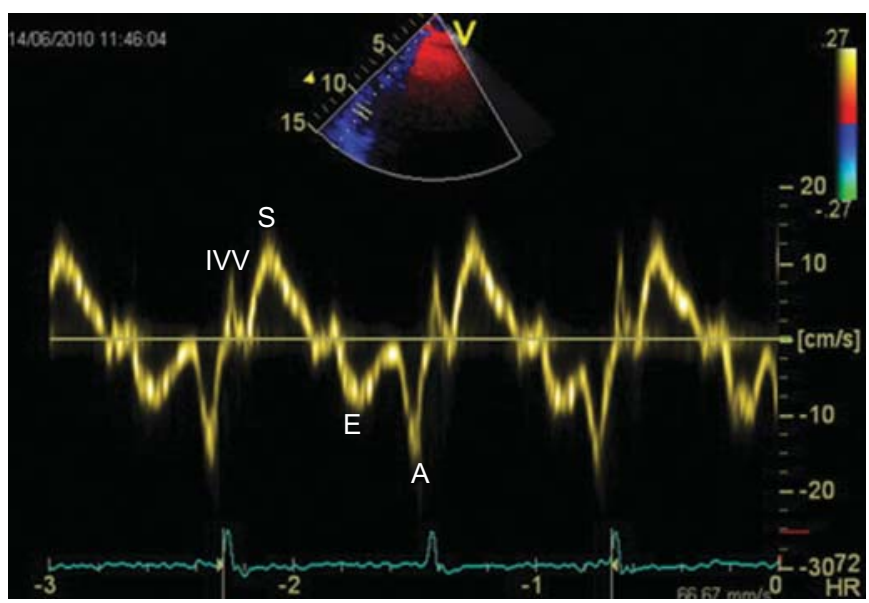

FIGURE 7. Tissue Doppler imaging (TDI) of the basal part of the right ventricle free wall allows the measurements on a single cardiac cycle of several parameters of right ventricular function, including systolic $(S)$ and diastolic ( $E$ and $A$ ) velocities, isovolumic contraction phase parameters, and TDI Tei index. IVV: isovolumic contraction velocity.

In a series of 53 patients with $\mathrm{PH}$, a Tei index value of $>0.83$ was found to be associated with an increased risk of clinical events and death (fig. 5) [63]. TAPSE also has a prognostic value; in a series including 63 patients with $\mathrm{PH}$, a TAPSE value of $<1.8 \mathrm{~cm}$ was associated with a poor prognosis and more severe right ventricular systolic dysfunction (fig. 6) [65]. Similarly, the systolic velocity of the tricuspid annulus assessed by TDI is associated with a prognostic value. In a series of 139 patients with heart failure, a systolic velocity of the tricuspid annulus $<10.8 \mathrm{~cm} \cdot \mathrm{s}^{-1}$ was associated with reduced survival [72].

A recent MRI study found that reduced stroke volume, reduced left ventricular volume and large right ventricular volume, as measured by MRI, also carried prognostic information in patients with $\mathrm{PH}$ [58]. Other echocardiographic parameters have been shown recently to have a prognostic value. BRIERRE et al. [27] studied 79 patients with $\mathrm{PH}$ and found that elevated $\bar{P}_{\mathrm{pa}}$ and diastolic $P$ pa, abnormal end-diastolic septal curve and an IVC diameter $>20 \mathrm{~mm}$ with reduced respiratory variation of diameter, were of prognostic value, even after adjustment for New York Heart Association functional class (NYHA FC) and 6-min walk distance (6MWD).

Finally, new techniques such as three-dimensional echocardiography and strain imaging could potentially improve the prognostic evaluation of these patients. Additional research is necessary to better assess the real value of echocardiography in the prognostic assessment of patients with $\mathrm{PH}$.

Echocardiography also plays a key role in the follow-up of patients with $\mathrm{PH}$ under specific therapy and the recent ESC/ ERS guidelines recommend follow-up echocardiography be performed 3-4 months after initiation or changes in specific therapy and in case of clinical worsening [1]. Repeat measurements of all echocardiographic parameters are mandatory in the follow-up of patients with $\mathrm{PAH}$, including P pa, cardiac output, and other parameters for comparison with baseline values. More importantly, the assessment of the reverse remodelling of right and left cardiac chambers is critical to assess the efficacy of specific therapy (fig. 8). A double-blind, randomised, placebo-controlled trial evaluated the effects of oral bosentan on the echocardiographic and Doppler parameters in 85 patients with PAH [73]. Compared with placebo, patients in the bosentan group had less right ventricular dilatation, a larger left ventricle, greater stroke volume, a higher cardiac index, and an improvement in right ventricular function and left ventricular early diastolic filling after 16 weeks of treatment. SeBBAG et al. [74] followed 16 patients with $\mathrm{PH}$ treated with epoprostenol and found that right ventricular function, as assessed by Tei index, was significantly depressed before therapy and improved after therapy, particularly in patients who also showed signs of clinical improvement.

New techniques, such as two-dimensional strain, will probably be helpful for the follow-up of patients with $\mathrm{PH}$ under specific therapy [70].

Echocardiographic study must be part of the goal-oriented strategy in patients with $\mathrm{PH}$ under specific therapy. Echocardiography must not be used alone for the follow-up and decision making in patients with $\mathrm{PH}$. A combination of echocardiographic parameters and other known prognostic parameters such as NYHA FC, 6MWD, brain natriuretic peptide measurement and haemodynamic parameters is recommended to assess both the prognosis and the efficacy of therapy.

\section{FUTURE DIRECTIONS}

The most dynamic developments in echocardiography, including its clinical applications related to the pulmonary circulation, took place three decades ago. Relatively new and not fully explored areas include clinical significance of tricuspid plane motion dynamics [66, 67], three-dimensional echocardiography of the right heart $[26,75]$ and modern methods of local RV strain rate assessment $[69,70]$. While a few of them increase the quality of individual patient evaluation [68], others mostly prolong an already extensive list of measurements, which are currently being taken during a resting echocardiographic examination aimed at diagnosing, staging or following up $\mathrm{PH}$. Two main directions of research should therefore focus on the selection of a few of the most useful existing echocardiographic variables measured at rest, and on the development, standardisation and prospective validation of echocardiographic stress testing, which could be more useful than resting echocardiographic assessment.

One way of selecting the most clinically relevant echocardiographic measurements for staging and follow-up of patients with $\mathrm{PH}$ is by implementing evidence from trials using gold standard methodology, such as MRI or RHC. For example, stroke volume index (SVI) and its changes over time emerge as promising haemodynamic variables potentially measurable with echocardiography. Recently confirmed by MRI [58], which has higher resolution and reproducibility, the prognostic value of stroke volume in $\mathrm{PH}$ has a straightforward pathophysiological justification. Importantly, stroke volume is independent from heart rate changes which can pseudonormalise cardiac output in the presence of potentially detrimental increased sympathetic system activity. Stroke 

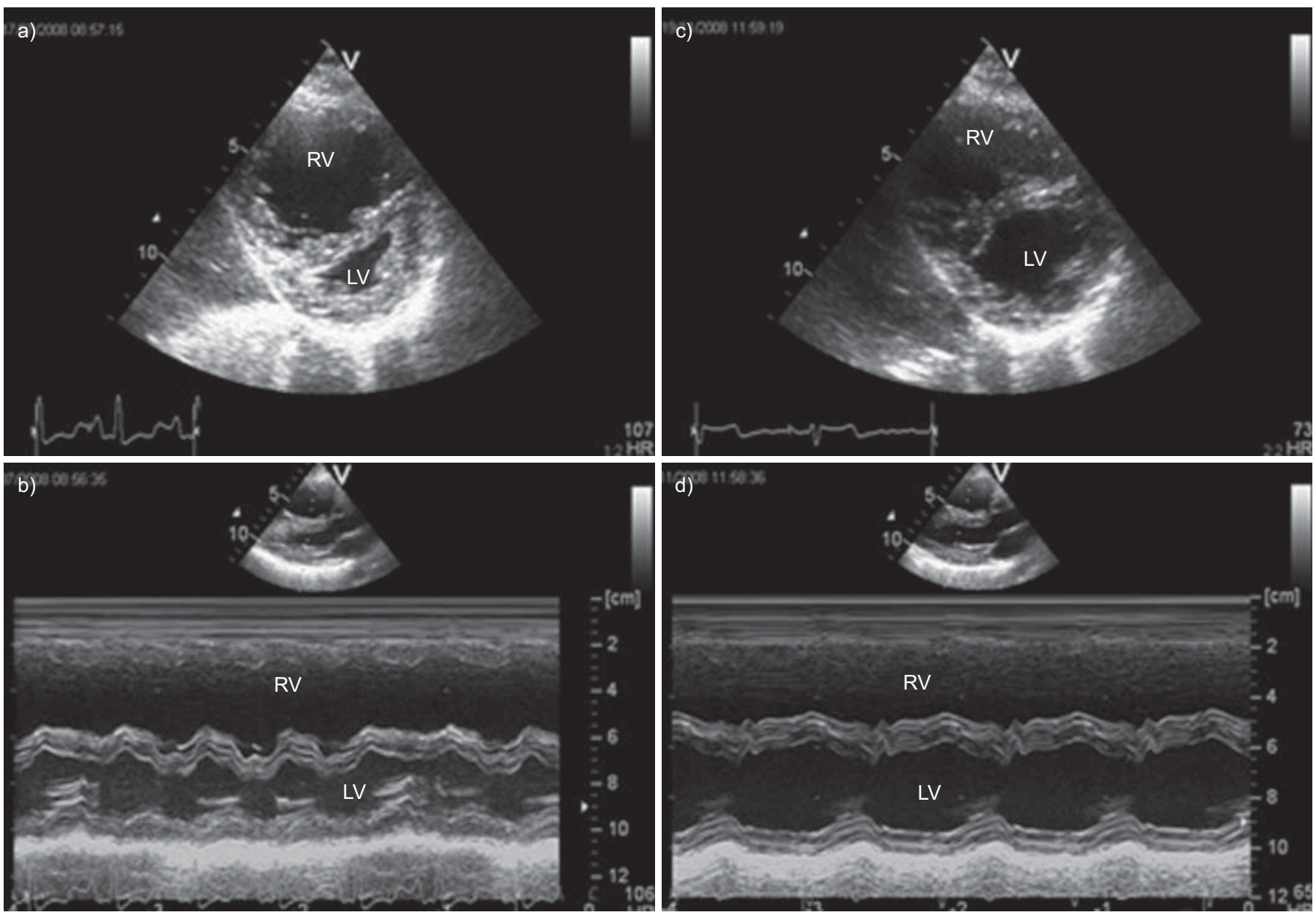

FIGURE 8. Reverse remodelling of left and right cavities under specific therapy in a patient with severe idiopathic pulmonary arterial hypertension. a) Before specific therapy: severe dilatation of the right ventricle (RV) with left ventricle (LV) compression, in two dimensional (a) and M-mode (b) echocardiography. After 4 months of combination therapy: partial regression of RV dilatation and LV compression (c and d)

volume is a well-established echocardiographic measurement, which can be taken both from both the right and left ventricular outflow tracts, to increase the accuracy of its estimation. The key source of error is related to the area of the orifice, and this should not affect the reproducibility of followup measurements, which could be limited to analysis of flow velocity tracing or even to the right ventricular ejection time. Indeed, stroke volume and right ventricular ejection time were among the variables that most significantly responded to targeted treatment with bosentan compared with placebo, as reported by a landmark echocardiographic trial [73]. Unpublished data from this trial suggested that an increase in right ventricular ejection time (rather than reduction of isovolumic contraction and relaxation times) was driving the beneficial changes in Tei index in patients in the active treatment arm, compared with placebo patients. During routine serial echocardiographic examinations, concentrating on the precise assessment of a very limited number of variables identified using a similar strategy as described for SVI and right ventricular ejection time, could reduce the information noise experienced when trying to follow an extensive number of poorly reproducible measurements. Clearly, prospective validation of clinical significance of such a limited set of variables, preferably compared with current comprehensive echocardiographic evaluation, would be required prior to any formal recommendations.

There is no doubt that information about the condition of any functional system is not complete without submitting it to stress. Unfortunately our understanding of the clinical significance of right heart haemodynamic changes induced by, for example, exercise is very rudimentary. This has been recently and somewhat painfully acknowledged by limiting the definition of $\mathrm{PH}$ to the resting value of $\bar{P}_{\mathrm{pa}} \geqslant 25 \mathrm{mmHg}$, while removing its component related to exercise [1]. Therefore, stress echocardiographic examinations, potentially useful for early detection of $\mathrm{PH}$, became, at least temporarily, unjustified. Indeed, though a term "hypertensive response" defined as TIPV $>3.08 \mathrm{~m} \cdot \mathrm{s}^{-1}$ was recently suggested to describe an exaggerated rise in $P$ pa,syst during exercise echocardiography at workload $<125 \mathrm{~W}$ or during prolonged breathing air with reduced oxygen content (inspired oxygen fraction 12\%), no upper limit of normal could be identified, as significant increases of $P$ pa,syst Doppler estimate were also observed during exercise in healthy controls [76].

However, stress echocardiography (understood as an exercise, controlled hypoxia or controlled volume loading test) does 
have great potential not only in screening for $\mathrm{PH}$ but also in follow-up and assessment of $\mathrm{PH}$ treatment. Again, implementation of new methods of functional assessment [77] standardisation of the tests and their validation should be undertaken in properly designed clinical trials.

Finally, echocardiography should also be prepared to face new challenges currently emerging in the field of $\mathrm{PH}$ and right ventricular function. This includes, for example, evaluation of right ventricular synchrony in preparation for the possibility of right ventricular resynchronisation therapy. Echocardiography should also allow for serial assessment of pulmonary artery diameter, recently suggested as related to the risk of sudden death in patients with $\mathrm{PH}$. Hopefully, the $\mathrm{PH}$ community will understand the remaining, hidden potential of echocardiography and will contribute to further development of this method in the field of pulmonary circulation [26].

\section{CONCLUSION}

Despite its several limitations, echocardiography remains the most clinically useful noninvasive method allowing for multidimensional assessment of pulmonary circulation. Echocardiography has a key role to play in the diagnosis of $\mathrm{PH}$ by identifying patients for whom RHC is warranted, facilitating earlier diagnosis and earlier medical management. The prognostic value of certain echocardiographic parameters is also recognised and the regular assessment of these, as part of a goal-oriented approach to therapy, is critical to monitor the progression of $\mathrm{PH}$ and the response of patients to specific treatment.

\section{STATEMENT OF INTEREST}

A. Torbicki has served as a consultant for Actelion, Eli Lilly, GlaxoSmithKline and mondoBIOTECH; received honoraria from Bayer Schering, Eli Lilly and Sanofi Aventis; and conducted research supported by Actelion, Bayer Schering, Bristol-Myers Squibb, Eli Lilly, GlaxoSmithKline, mondoBIOTECH and Pfizer.

\section{ACKNOWLEDGEMENTS}

We received minor editorial assistance from J. Heagerty, Elements Communications Ltd (Westerham, UK), supported by Actelion Pharmaceuticals Ltd (Allschwil, Switzerland).

\section{REFERENCES}

1 Galiè N, Hoeper MM, Humbert M, et al. Guidelines for the diagnosis and treatment of pulmonary hypertension: the Task Force for the Diagnosis and Treatment of Pulmonary Hypertension of the European Society of Cardiology (ESC) and the European Respiratory Society (ERS), endorsed by the International Society of Heart and Lung Transplantation (ISHLT). Eur Respir J 2009; 34: 1219-1263.

2 Danchin N, Cornette A, Henriquez A, et al. Two-dimensional echocardiographic assessment of the right ventricle in patients with chronic obstructive lung disease. Chest 1987; 92: 229-233.

3 Zenker G, Forche G, Harnoncourt K. Two-dimensional echocardiography using a subcostal approach in patients with COPD. Chest 1985; 88: 722-725.

4 Oswald-Mammosser M, Oswald T, Nyankiye E, et al. Noninvasive diagnosis of pulmonary hypertension in chronic obstructive pulmonary disease. Comparison of ECG, radiological measurements, echocardiography and myocardial scintigraphy. Eur J Respir Dis 1987; 71: 419-429.
5 Kitabatake A, Inoue M, Asao M, et al. Noninvasive evaluation of pulmonary hypertension by a pulsed Doppler technique. Circulation 1983; 68: 302-309.

6 Turkevich D, Groves BM, Micco A, et al. Early partial systolic closure of the pulmonic valve relates to severity of pulmonary hypertension. Am Heart J 1988; 115: 409-418.

7 Marangoni S, Quadri A, Dotti A, et al. Noninvasive assessment of pulmonary hypertension: a simultaneous echo-Doppler hemodynamic study. Cardiology 1988; 75: 401-408.

8 Robinson PJ, Macartney FJ, Wyse RK. Non-invasive diagnosis of pulmonary hypertension. Int J Cardiol 1986; 11: 253-259.

9 Torbicki A, Tramarin R, Fracchia F, et al. Reliability of pulsed wave Doppler monitoring of acute changes in pulmonary artery pressure in patients with chronic obstructive pulmonary disease. Progr Respir Res 1990; 26: 133-141.

10 Mallery JA, Gardin JM, King SW, et al. Effects of heart rate and pulmonary artery pressure on Doppler pulmonary artery acceleration time in experimental acute pulmonary hypertension. Chest 1991; 100: 470-473.

11 Matsuda M, Sekiguchi T, Sugishita $Y$, et al. Reliability of noninvasive estimates of pulmonary hypertension by pulsed Doppler echocardiography. Br Heart J 1986; 56: 158-164.

12 Isobe M, Yazaki Y, Takaku F, et al. Prediction of pulmonary arterial pressure in adults by pulsed Doppler echocardiography. Am J Cardiol 1986; 57: 316-321.

13 Okamoto M, Miyatake K, Kinoshita N, et al. Analysis of blood flow in pulmonary hypertension with the pulsed Doppler flowmeter combined with cross sectional echocardiography. Br Heart J 1984; 51: 407-415.

14 Panidis IP, Ross J, Mintz GS. Effect of sampling site on assessment of pulmonary artery blood flow by Doppler echocardiography. Am J Cardiol 1986; 58: 1145-1147.

15 Gardin JM, Davidson DM, Rohan MK, et al. Relationship between age, body size, gender, and blood pressure and Doppler flow measurements in the aorta and pulmonary artery. Am Heart J 1987; 113: 101-109.

16 Naeije R, Torbicki A. More on the noninvasive diagnosis of pulmonary hypertension: Doppler echocardiography revisited. Eur Respir J 1995; 8: 1445-1449.

17 Torbicki A, Kurzyna M, Ciurzynski M, et al. Proximal pulmonary emboli modify right ventricular ejection pattern. Eur Respir J 1999; 13: 616-621.

18 Skjaerpe T, Hatle L. Noninvasive estimation of systolic pressure in the right ventricle in patients with tricuspid regurgitation. Eur Heart J 1986; 7: 704-710.

19 Masuyama T, Kodama K, Kitabatake A, et al. Continuous-wave Doppler echocardiographic detection of pulmonary regurgitation and its application to noninvasive estimation of pulmonary artery pressure. Circulation 1986; 74: 484-492.

20 Matsuoka Y, Hayakawa K. Noninvasive estimation of right ventricular systolic pressure in ventricular septal defect by a continuous wave Doppler technique. Jpn Circ J 1986; 50: 1062-1070.

21 Marx GR, Allen HD, Goldberg SJ. Doppler echocardiographic estimation of systolic pulmonary artery pressure in pediatric patients with interventricular communications. J Am Coll Cardio 1985; 6: 1132-1137.

22 Musewe NN, Poppe D, Smallhorn JF, et al. Doppler echocardiographic measurement of pulmonary artery pressure from ductal Doppler velocities in the newborn. J Am Coll Cardiol 1990; 15 446-456.

23 Yock PG, Popp RL. Noninvasive estimation of right ventricular systolic pressure by Doppler ultrasound in patients with tricuspid regurgitation. Circulation 1984; 70: 657-662

24 Beard JT, Byrd BF III. Saline contrast enhancement of trivial Doppler tricuspid regurgitation signals for estimating pulmonary artery pressure. Am J Cardiol 1988; 62: 486-488. 
25 Himelman RB, Struve SN, Brown JK, et al. Improved recognition of cor pulmonale in patients with severe chronic obstructive pulmonary disease. Am J Med 1988; 84: 891-898.

26 Badano L, Ginghina C, Easaw J, et al. Right ventricle in pulmonary arterial hypertension: haemodynamics, structural changes, imaging, and proposal of a study protocol aimed to assess remodelling and treatment effects. Eur J Echocardiography 2010; 11: 27-37.

27 Brierre G, Blot-Souletie N, Degano B, et al. New echocardiographic prognostic factors for mortality in pulmonary arterial hypertension. Eur J Echocardiogr 2010; 11: 516-522.

28 Hinderliter AL, Willis PW, Barst RJ, et al. Effects of long-term infusion of prostacyclin (epoprostenol) on echocardiographic measures of right ventricular structure and function in primary pulmonary hypertension. Primary Pulmonary Hypertension Study Group. Circulation 1997; 95: 1479-1486.

29 Liem RI, Young LT, Lay AS, et al. Reproducibility of tricuspid regurgitant jet velocity measurements in children and young adults with sickle cell disease undergoing screening for pulmonary hypertension. Am J Hematol 2010; 85: 741-745.

30 Fisher MR, Forfia PR, Chamera E, et al. Accuracy of Doppler echocardiography in the hemodynamic assessment of pulmonary hypertension. Am J Respir Crit Care Med 2009; 179: 615-621.

31 Lei MH, Chen JJ, Ko YL, et al. Reappraisal of quantitative evaluation of pulmonary regurgitation and estimation of pulmonary artery pressure by continuous wave Doppler echocardiography. Cardiology 1995; 86: 249-256.

32 Ensing G, Seward J, Darragh R, et al. Feasibility of generating hemodynamic pressure curves from noninvasive Doppler echocardiographic signals. J Am Coll Cardiol 1994; 23: 434-442.

33 Chemla D, Castelain V, Humbert M, et al. New formula for predicting mean pulmonary artery pressure using systolic pulmonary artery pressure. Chest 2004; 126: 1313-1317.

34 Chemla D, Castelain V, Provencher S, et al. Evaluation of various empirical formulas for estimating mean pulmonary artery pressure by using systolic pulmonary artery pressure in adults. Chest 2009; 135: 760-768.

35 McQuillan BM, Picard MH, Leavitt M, et al. Clinical correlates and reference intervals for pulmonary artery systolic pressure among echocardiographically normal subjects. Circulation 2001; 104: 27972802.

36 Mukerjee D, St George D, Knight C, et al. Echocardiography and pulmonary function as screening tests for pulmonary arterial hypertension in systemic sclerosis. Rheumatology (Oxford) 2004; 43: 461-466.

37 Launay D, Mouthon L, Hachulla E, et al. Prevalence and characteristics of moderate to severe pulmonary hypertension in systemic sclerosis with and without interstitial lung disease. J Rheumatol 2007; 34: 1005-1011.

38 Vonk M, Coghlan G, Bonderman D, et al. The DETECT study: a two-stage, prospective, observational, cohort study in scleroderma patients to evaluate screening tests and the incidence of pulmonary arterial hypertension and pulmonary hypertension. Clin Exp Rheumatol 2010; 28: Suppl., 55.

39 Hachulla E, Gressin V, Guillevin L, et al. Early detection of pulmonary arterial hypertension in systemic sclerosis: a French nationwide prospective multicenter study. Arthritis Rheum 2005; 52: 3792-3800

40 Sitbon O, Lascoux-Combe C, Delfraissy JF, et al. Prevalence of HIV-related pulmonary arterial hypertension in the current antiretroviral therapy era. Am J Respir Crit Care Med 2008; 177: 108-113.

41 Klok FA, van Kralingen KW, van Dijk AP, et al. Prospective cardiopulmonary screening program to detect chronic thromboembolic pulmonary hypertension in patients after acute pulmonary embolism. Haematologica 2010; 95: 970-975.

42 Surie S, Gibson NS, Gerdes VE, et al. Active search for chronic thromboembolic pulmonary hypertension does not appear indicated after acute pulmonary embolism. Thromb Res 2010; 125: e202-5.

43 Krowka MJ, Swanson KL, Frantz RP, et al. Portopulmonary hypertension: results from a 10-year screening algorithm. Hepatology 2006; 44: 1502-1510.

44 D'Alonzo GE, Barst RJ, Ayres SM, et al. Survival in patients with primary pulmonary hypertension: results from a national prospective registry. Ann Intern Med 1991; 115: 343-349.

45 Kuhn KP, Byrne DW, Arbogast PG, et al. Outcome in 91 consecutive patients with pulmonary arterial hypertension receiving epoprostenol. Am J Respir Crit Care Med 2003; 167: 580-586.

46 Humbert $\mathrm{M}$, Sitbon $\mathrm{O}$, Chaouat $\mathrm{A}$, et al. Pulmonary arterial hypertension in France: results from a national registry. Am J Respir Crit Care Med 2006; 173: 1023-1030.

47 Humbert M, Sitbon O, Chaouat A, et al. Survival in patients with idiopathic, familial, and anorexigen-associated pulmonary arterial hypertension in the modern management era. Circulation 2010; 122: $156-163$.

48 Kawut SM, Taichman DB, Archer-Chicko CL, et al. Hemodynamics and survival in patients with pulmonary arterial hypertension related to systemic sclerosis. Chest 2003; 123: 344-350.

49 Bossone E, Bodini BD, Maza A, et al. Pulmonary arterial hypertension. The key role of echocardiography. Chest 2005; 127: 1836-1843.

50 Burgess MI, Bright-Thomas RJ, Ray SG. Echocardiographic evaluation of right ventricular function. Eur J Echocardiography 2002; 3: 252-262.

51 Haddad F, Hunt SA, Rosenthal DN, et al. Right ventricular function in cardiovascular disease, part I: anatomy, physiology, aging, and functional assessment of the right ventricle. Circulation 2008; 117: 1436-1448.

52 Bossone E, Duong-Wagner TH, Paciocco G, et al. Echocardiographic features of primary pulmonary hypertension. J Am Soc Echocardiogr 1999; 12: 655-662.

53 Lang RM, Bierig M, Devereux RB, et al. Recommendations for chamber quantification. Eur J Echocardiogr 2006; 7: 79-108.

54 Perrone S, De La Fuente RL, et al. Right atrial size and tricuspid regurgitation severity predict mortality or transplantation in primary pulmonary hypertension. J Am Soc Echocardiogr 2002; 15: 1160-1164.

55 Jiang L, Levine RA, Weyman AE. Echocardiographic assessment of right ventricular volume and function. Echocardiography 1997; 14: $189-205$.

56 Raymond RJ, Hinderliter AL, Willis PW, et al. Echocardiographic predictors of adverse outcomes in primary pulmonary hypertension. J Am Coll Cardiol 2002; 39: 1214-1219.

57 Ryan T, Petrovic O, Dillon JC, et al. An echocardiographic index for separation of right ventricular volume and pressure overload. J Am Coll Cardiol 1985; 5: 918-927.

58 van Wolferen SA, Marcus JT, Boonstra A, et al. Prognostic value of right ventricular mass, volume, and function in idiopathic pulmonary arterial hypertension. Eur Heart J 2007; 28: 1250-1257.

59 Naito H, Arisawa J, Harada K, et al. Assessment of right ventricular regional contraction and comparison with the left ventricle in normal humans: a cine magnetic resonance study with presaturation myocardial tagging. Br Heart J 1995; 74: 186-191.

60 Jurcut R, Giusca S, La Gerche A, et al. The echocardiographic assessment of the right ventricle: what to do in 2010? Eur J Echocardiogr 2010; 11: 81-96.

61 Anavekar NS, Gerson D, Skali H, et al. Two dimensional assessment of right ventricular function: an echocardiographicMRI correlative study. Echocardiography 2007; 24: 452-456.

62 Tei C, Dujardin KS, Hodge DO, et al. Doppler echocardiographic index for assessment of global right ventricular function. J Am Soc Echocardiogr 1996; 9: 838-847.

63 Yeo TC, Dujardin KS, Tei C, et al. Value of a Doppler-derived index combining systolic and diastolic time intervals in predicting 
outcome in primary pulmonary hypertension. Am J Cardiol 1998; 81: 1157-1161.

64 Harada K, Tamura M, Toyono M, et al. Comparison of the right ventricular Tei index by tissue Doppler imaging to that obtained by pulsed Doppler in children without heart disease. Am J Cardiol 2002; 90: 566-569.

65 Forfia PR, Fisher MR, Mathai SC, et al. Tricuspid annular displacement predicts survival in pulmonary hypertension. Am J Respir Crit Care Med 2006; 174: 1034-1041.

66 Ueti OM, Camargo EE, Ueti Ade A, et al. Assessment of right ventricular function with Doppler echocardiographic indices derived from tricuspid annular motion: comparison with radionuclide angiography. Heart 2002; 88: 244-248.

67 Meluzín J, Špinarová L, Bakala J, et al. Pulsed Doppler tissue imaging of the velocity of tricuspid annular systolic motion; a new, rapid, and non-invasive method of evaluating right ventricular systolic function. Eur Heart J 2001; 22: 340-348.

68 Vogel M, Schmidt MR, Kristiansen SB, et al. Validation of myocardial acceleration during isovolumic contraction as a novel noninvasive index of right ventricular contractility: comparison with ventricular pressure-volume relations in an animal model. Circulation 2002; 105: 1693-1699.

69 Schattke S, Knebel F, Grohmann A, et al. Early right ventricular systolic dysfunction in patients with systemic sclerosis without pulmonary hypertension: a Doppler tissue and speckle tracking echocardiography study. Cardiovascular Ultrasound 2010; 8: 3-11.

70 Borges AC, Knebel F, Eddicks S, et al. Right ventricular function assessed by two-dimensional strain and tissue Doppler echocardiography in patients with pulmonary arterial hypertension and effect of vasodilator therapy. Am J Cardiol 2006; 98: 530-534.

71 Hinderliter AL, Willis PW 4th, Long W, et al. Frequency and prognostic significance of pericardial effusion in primary pulmonary hypertension. Am J Cardiol 1999; 84: 481-484.

72 Meluzín J, Špinarová L, Dušek L, et al. Prognostic importance of the right ventricular function assessed by Doppler tissue imaging. Eur J Echocardiogr 2003; 4: 262-271.

73 Galiè N, Hinderliter $\mathrm{Al}$, Torbicki $\mathrm{A}$, et al. Effects of the oral endothelin-receptor antagonist bosentan on echocardiographic and Doppler measures in patients with pulmonary arterial hypertension. J Am Coll Cardiol 2003; 41: 1380-1386.

74 Sebbag I, Rudski LG, Therrien J, et al. Effect of chronic infusion of epoprostenol on echocardiographic right ventricular myocardial performance index and its relation to clinical outcome in patients with primary pulmonary hypertension. Am J Cardiol 2001; 88: 1060-1063.

75 Grapsa J, O'Regan DP, Pavlopoulos $\mathrm{H}$, et al. Right ventricular remodelling in pulmonary arterial hypertension with threedimensional echocardiography: comparison with cardiac magnetic resonance imaging. Eur J Echocardiogr 2010; 11: 64-73.

76 Grunig E, Weissmann S, Ehlken N, et al. Stress Doppler echocardiography in relatives of patients with idiopathic and familial pulmonary arterial hypertension: results of a multicenter European analysis of pulmonary artery pressure response to exercise and hypoxia. Circulation 2009; 119: 1747-1757.

77 Yang HS, Mookadam F, Warsame TA, et al. Evaluation of right ventricular global and regional function during stress echocardiography using novel velocity vector imaging. Eur J Echocardiogr 2010; 11: 157-164. 